\title{
Elektronik Fetal Monitorizasyon Sonucunun Apgar Skor Sistemi \\ Değeriyle Karşılaştırılması
}

The Comparison of the Electronic Fetal Monitoring Results with the

Scores on Apgar Scoring System

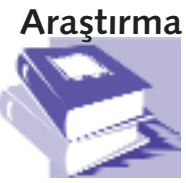

Research

Gülbahtiyar Demirel ${ }^{1}$, Gülseren Dağlar ${ }^{2}$, Dilek Bilgiç̧

DOI: $10.17942 /$ sted.484165

Öz

Amaç: Çalışma, vajinal doğumdan önceki son çekilen EFM sonucuyla doğumdan sonra yenidoğanın Apgar skorlama sisteminin değerini karşılaştırmak amacıyla yapılmıştır.

Gereç ve Yöntem: Bu çalışma Kasım 2014-Mayıs 2015 tarihlerinde Sivas Devlet Hastanesi'nde yapılmıştır. Örneklemi araştırma kriterlerine uyan 485 kadın oluşturmuştur. Veriler 15 soruluk anket formu kullanılarak toplanmıştır. Verilerin değerlendirilmesi SPSS (14.0) paket programında ortalama, standart sapma, yüzde, $t$ testi ve ki-kare testi kullanılmıs, istatistiksel anlamlılık $p<0.05$ olarak kabul edilmiştir.

Bulgular: Reaktif EFM sonucuna göre 1. dakika Apgar skoru ortalaması 7,81 $\pm 0,63$ iken, 5. dakika Apgar skoru ortalaması 9,26 $\pm 0,68$ 'dir $(p<0.05)$. Nonreaktif EFM sonucuna göre 1. dakika Apgar skoru ortalaması 6,61 $\pm 0,60$ iken, 5. dakika Apgar skoru ortalaması 8,32 $\pm 0,62$ 'dir $(p<0.05)$.

Sonuç: Vajinal doğumdan önce son çekilen EFM sonucu reaktif olduğunda yenidoğanın Apgar skoru değeri yüksek iken nonreaktif olduğunda Apgar skor değerinin düşük olduğu belirlenmiştir.

Anahtar sözcükler: Fetal izlem, Apgar skoru, Doğum, Yenidoğan
Geliş/Received : 16.11.2018

Kabul/Accepted : 23.04.2019
Abstract
Objective: The study was conducted to compare the result of EFM most recently performed before vaginal delivery with newborn infant's Apgar score measured after birth.

Materials and Method: This study was carried out at Sivas State Hospital between November 2014 and May 2015. The sample consisted of 485 women meeting the inclusion criteria for the research. The data were collected using a 15-item questionnaire. Mean, standard deviation, percentage, chi-square test and t-test were used in the evaluation of the data through SPSS 14.0 software. Statistical significance was considered to be $p<0.05$

Findings: According to the reactive results of EFM, while the average of 1-minute Apgar scores was $7,81 \pm 0,63$, the mean Apgar score at 5 minutes after birth was $9,26 \pm 0,68(p<0.05)$. According to the non-reactive EFM results, while the average of 1-minute Apgar scores was $6,61 \pm 0,60$, the mean Apgar score at 5 minutes was $8,32 \pm 0,62$ $(p<0.05)$.

Conclusion: It was concluded that the Apgar score of newborn was high when the result of EFM most recently performed before vaginal delivery was reactive, Apgar score of the newborn was low when the result was non-reactive.

Key words: Fetal monitoring, Apgar score, Birth, Newborn

1 Doç. Dr.; Sivas Cumhuriyet Ü. Sağlık Bilimleri Fak. Ebelik Bölümü, Sivas (Orcid No: 0000-0003-2258-7757)

2 Dr. Öğr. Üyesi; Sivas Cumhuriyet Ü. Sağlık Bilimleri Fak. Ebelik Bölümü, Sivas, (Orcid No: 0000-0001-7159-5011

3 Doç. Dr.; Dokuz Eylül Ü. Hemşirelik Fak. İzmir (Orcid No: 0000-0001-9569-8875) 


\section{Giriş}

Günümüzde fetusun en iyi bakımı alması gerekliliği gündeme gelmiştir (1). Bu nedenle doğum eylemi sırasında fetal durumun tespiti önemli olup fetal ve perinatal mortalitenin önlenmesi amacına yönelinmiştir (2-4). Perinatal asfiksinin büyük bir bölümü intrauterin gerçekleştiğinden asfiksinin erken saptanması prognoz açısından çok önemlidir (5-7). Fetal hipoksi sonrasında meydana gelecek olaylar hipoksik ensefalopatiye ya da hipoksik hasara yol açabilmektedir. Fetal asfiksiye bağlı fetal ölüm ve nörolojik sekellerin en aza indirilmesi için, doğum eyleminde fetal hipoksi tespit edilmelidir (2$4,7,8)$.

Intrauterin fetal durum ve distresin değerlendirilmesinde çeşitli parametreler (elektronik fetal monitorizasyon (EFM), kontraksiyon stres test (CST), fetal biyofizik profil, amniyon sıvı indeksi, doppler, skalp kan örnekleri, umblikal kord kanında laktat, arginin, vazopressin, izoenzimler ve katekolaminlerin saptanması ile umblikal kordon kan gazları ve yenidoğanda Apgar skorlaması) kullanılmaktadır $(2,7)$. Bu parametrelerden birisi olan intrapartum fetal izlem, erken dönemde asfiksi tanısı koyarak fetal ve erken neonatal mortaliteyi, fetal ve perinatal morbiditeyi azaltmaktadır (1,5,6,9-11). EFM; elektronik yoldan myometrium kasılmaları ile fetal kalp hızının senkron olarak yazdırımasıdır. Fetal distresinin belirlenmesinde; EFM en sık kullanılan obstetrik tanı yöntemlerinden birisidir $(3,6,7)$.

Günümüzde intrauterin fetal durum ve distresin değerlendirilmesinde $\operatorname{EFM}(5,6,9,12)$ ve 1953 yılında Dr. Virginia Apgar tarafından geliştirilen Apgar skorlama sistemi kolay ve hızlı yöntemler olarak kullanılmaktadırlar (13). Yenidoğanın klinik durumunu değerlendirmek ve solunumun sağlanması için acil girişim gerekliliğini tespit etmek amacıyla geliştirilen Apgar skorlama sistemi, doğumdan sonra bebeklerin standart biçimde değerlendirilerek distresin tanımlanmasına olanak sağlar (14). Apgar skorlama sistemine yenidoğan ünitelerinde, EFM'ye intrapartum dönemde sıklıkla başvurulmaktadır. Ancak günümüzde bu kadar yaygın kullanılmalarına rağmen EFM sonucu ve Apgar skorlama sisteminin değerini kuşkuyla karşılayan çalışmaların sayısı giderek artmaktadır
$(7,10,14,15)$. Bu nedenle bu çalışma; vajinal doğumdan önceki son çekilen EFM sonucuyla doğumdan sonra yenidoğanın Apgar skorlama sisteminin değerini karşılaştırmak amacıyla yapılmıştır.

\section{Gereç ve Yöntem \\ Araştırmanın Tipi}

Bu çalışma tanımlayıcı kesitsel araştırma tipindedir.

\section{Araştırmanın Yapıldığı Yer}

Çalışma, Türkiye'de bir devlet hastanesinde (Sivas Devlet Hastanesi) 20 Kasım 2014 / 25 Mayıs 2015 tarihleri arasında planlanmıştır.

\section{Araştırmanın Evreni ve Örneklemi}

Çalışmaya doğum servisine doğum için başvuran, örnekleme alınma kriterlerine uyan (gebelik haftasının 38-42 hafta arasında olması, hipertansiyon ya da hipotansiyon olmaması, intrauterin gelişme geriliği olmaması, fetüsün kilosunun 2500 / 4500 gr arasında olması, fetal aritmi olmaması, tekiz gebelik olması, sezaryen doğum öyküsü olmaması, normal vajinal doğum yapmayı engelleyecek gebe ve fetüste akut ya da kronik problem olmaması vb.) 485 gebe alınmıştır.

\section{Veri Toplama Araçları}

Veriler araştırmacılar tarafından literatür taraması sonucunda oluşturulan gebelerin tanımlayıcı özellikleri, son EFM trasesi parametrelerinin ve sonucunun da içerisinde yer aldığı EFM çekilen ve doğum yapılan pozisyon, indüksiyon kullanımı, prezante olan kısım, 1. ve 5. dakika Apgar skoru gibi değerlerin yer aldığı 15 soruluk anket formu kullanılarak toplanmıştır $(3,4,7,13-15)$.

\section{3 yılında Dr. Virginia Apgar tarafından} yenidoğanın canlılığının kantitatif olarak değerlendirilmesi için geliştirilen skorlama sistemi, hemen hemen tüm yenidoğan ünitelerinde, çocuğun doğumdaki durumunu belirlemede kolay ve hızlı bir yöntem olarak kullanılmaktadır. Amacı daha yakın bir gözlem için özendirici olmak ve bebeklerin klinik durumunun daha kesin bir biçimde değerlendirilmesini sağlamaktır. Apgar, bu yaklaşımın ağır derecede asfiksiye maruz kalmış yenidoğanın yanlış değerlendirilmesini ve böylece yetersiz tedavi edilmelerini önleyeceğini, sağlıklı olanların ise 
gereksiz yere oksijen tedavisi ya da diğer girişimlere maruz kalmamalarını sağlayacağını ümit etmiştir (7). Apgar skorlama sistemine göre, yenidoğan doğumdan sonra 1. ve 5. dakikada değerlendirilir ve gerekiyorsa skorlama 5 dakikada bir tekrarlanır (Tablo 1). Apgar skorlaması 5 objektif parametreye dayanır: 1 . Kalp tepe atımı, 2. Solunum şekli, 3. Kas tonusu, 4. Deri rengi, 5. Uyarıya cevap.

Her bir parametreye 0, 1 ve 2 puan verilmektedir. Her bir parametre için verilen puanlar toplanır. 710 puan arasında olan değerler sağlıklı yenidoğan olarak değerlendirilirken, 4-6 puan arası orta, 0-3 puan arası ağır depresyon olarak nitelendirilmektedir (7).

\section{Araştırmanın Uygulanması}

Araştırmaya katılmaya gönüllü olduğuna dair yazılı onam veren gebelere formlar araştırmacı tarafından yüz yüze görüşme tekniği kullanılarak uygulanmıştır. Araştırmacı tarafından çekilen vajinal doğumdan önceki son EFM sonucuyla, yine araştırmacı tarafından değerlendirilen doğumdan sonra yenidoğanın 1. ve 5. dakika Apgar skorlama sisteminin değeri karşılaştırılmıştır.

\section{Verilerin Değerlendirilmesi}

Çalışmadan elde edilen verilerin değerlendirilmesinde, ortalama ve standart sapma değerleri, iki ortalama arasındaki farkın önemlilik testi, iki eş arasındaki farkın önemlilik testi, kikare testi uygulanmıştır. Verilerin değerlendirilmesinde istatistiksel anlamlılık 0.05 önem düzeyinde incelenmiş olup SPSS 14 versiyonu kullanılmıştır.

\section{Araştırmanın Etik Boyutu}

Araştırmanın uygulanmasından önce Sivas il Sağlık Müdürlüğünden gerekli yazılı izin ve
Cumhuriyet Üniversitesi Girişimsel Olmayan Klinik Araştırmalar Etik Kurulundan etik onay alındı (Etik Karar No: 2014-09/21). Formlar uygulanmadan önce Helsinki deklarasyonu ilkelerine uyuldu. Katılımcılara çalışmanın amacı açıklandı, elde edilen bilgilerin çalışma dışında kullanılmayacağı, kişisel bilgilerinin gizliliğinin korunacağı hakkında bilgi verildi. Sözel ve yazılı onamları alındı ve daha sonra formlar uygulandı.

\section{Bulgular}

Araştırmaya katılan gebelerin; \% 74,7'sinin gebelik sayısı 1-2, \% 78,8'inin gebelik haftası 3840, \%33,8'inin tansiyonu 110/60 mmHg'dır. Doğum eylemi sırasında gebelerin; \% 100,0'ının EFM çekim pozisyonu sol yan, $\% 60,4$ 'üne indüksiyon uygulanmazken, \%60,0'ına ilaç uygulanmıştır. İlaç uygulanan gebelerin $\% 66,0$ 'ına valethamat bromid-parasetamol ve sentetik oksitosin uygulaması yapılmıştır. Gebelerin tamamında $(\% 100,0)$ doğum sırasındaki pozisyon litotomi iken fetüsün prezante olan kısmı baştır. Doğum eylemi esnasında gebelerin; \% 16,5'inde amniyotik sıvının mekonyumlu olduğu, \%23,7'sine müdahale yapıldığı, \%100,0'ına müdahale olarak epizyotomi açıldığı belirlenmiştir (Tablo 2).

EFM parametreleri açısından bakıldığında gebelerin; \%95,1'inde taşikardi ya da bradikardi, $\% 89,5$ 'inde deselerasyon olmadığı, \% 100,0'ında variabilite, \%98,1'inde akselerasyon olduğu belirlenmiştir. Bu parametreler doğrultusunda gebelerin \% 89,9'unun EFM sonucunun reaktif olduğu saptanmıştır (Tablo 2).

Gebelerin yaş ortalaması $25,8 \pm 5,5$ iken nabız

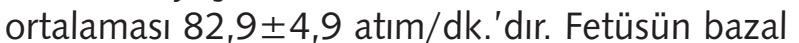
kalp atım hızı ortalaması 140,4 $\pm 11,4$ mmHg'dır. Gebelerin doğum eyleminin 2. evre süre

Tablo 1. Apgar skorlama sistemi

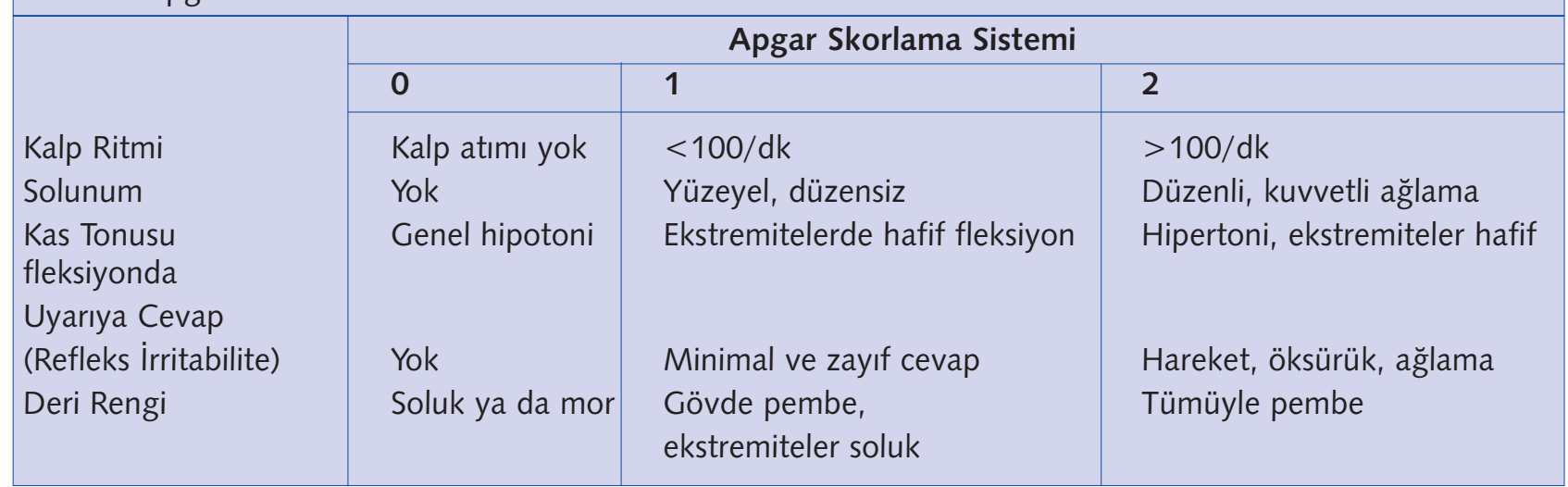




\begin{tabular}{|c|c|c|}
\hline $\begin{array}{l}\text { Gebelerin bazı sosyo-demografik } \\
\text { ve doğum eylemi sırasındaki özellikleri }\end{array}$ & $\mathrm{n}$ & $\%$ \\
\hline \multicolumn{3}{|l|}{ Gebelik sayısı } \\
\hline Bir & 240 & 49,5 \\
\hline iki & 122 & 25,2 \\
\hline Üç & 94 & 19,4 \\
\hline Dört & 25 & 5,2 \\
\hline Beş & 1 & 0,2 \\
\hline Altı ve üzeri & 3 & 0,6 \\
\hline \multicolumn{3}{|l|}{ Gebelik haftası } \\
\hline 38-40 hafta & 382 & 78,8 \\
\hline 41-42 hafta & 103 & 21,2 \\
\hline \multicolumn{3}{|l|}{ Tansiyon } \\
\hline $100 / 60 \mathrm{mmHg}$ & 123 & 25,4 \\
\hline $90 / 60 \mathrm{mmHg}$ & 140 & 28,9 \\
\hline $110 / 60 \mathrm{mmHg}$ & 164 & 33,8 \\
\hline $120 / 70 \mathrm{mmHg}$ & 58 & 12,0 \\
\hline \multicolumn{3}{|l|}{ EFM çekim pozisyonu } \\
\hline Sol yan pozisyon & 485 & 100,0 \\
\hline \multicolumn{3}{|l|}{ Doğumda indüksiyon kullanımı } \\
\hline Kullanıldı & 192 & 39,6 \\
\hline Kullanılmadı & 293 & 60,4 \\
\hline \multicolumn{3}{|l|}{ Doğumda ilaç kullanımı } \\
\hline Kullanıldı & 291 & 60,0 \\
\hline Kullanılmadı & 194 & 40,0 \\
\hline \multicolumn{3}{|l|}{ Doğumda kullanılan ilaç } \\
\hline Valethamat bromid-parasetamol & 99 & 34,0 \\
\hline $\begin{array}{l}\text { Valethamat bromid-parasetamol } \\
\text { ve sentetik oksitosin }\end{array}$ & 192 & 66,0 \\
\hline Toplam & 291 & 100,0 \\
\hline Fetüsün prezente olan kısmı & & \\
\hline Baş & 485 & 100,0 \\
\hline \multicolumn{3}{|l|}{ Mekonyumlu amniyotik sıvı durumu } \\
\hline Var & 80 & 16,5 \\
\hline Yok & 405 & 83,5 \\
\hline \multirow{2}{*}{\multicolumn{3}{|c|}{$\begin{array}{l}\text { EFM Değerlendirme Kriteri } \\
\text { Taşikardi ya da bradikardi durumu }\end{array}$}} \\
\hline & & \\
\hline Var & 24 & 4,9 \\
\hline Yok & 461 & 95,1 \\
\hline \multicolumn{3}{|l|}{ Variabilite durumu } \\
\hline Var & 485 & 100,0 \\
\hline \multicolumn{3}{|l|}{ Akselerasyon durumu } \\
\hline Var & 476 & 98,1 \\
\hline Yok & 9 & 1,9 \\
\hline \multicolumn{3}{|l|}{ Deselerasyon durumu } \\
\hline Var & 51 & 10,5 \\
\hline Yok & 434 & 89,5 \\
\hline \multicolumn{3}{|l|}{ Sonuç } \\
\hline Reaktif & 436 & 89,9 \\
\hline Nonreaktif & 49 & 10,1 \\
\hline \multicolumn{3}{|l|}{ Doğumda kullanılan pozisyon } \\
\hline Litotomi & 485 & 100,0 \\
\hline \multicolumn{3}{|l|}{ Doğumun 2. evresinde müdahale durumu } \\
\hline Yapıldı & 115 & 23,7 \\
\hline Yapılmadı & 370 & 76,3 \\
\hline \multicolumn{3}{|l|}{ Doğumun 2. evresinde yapılan müdahale } \\
\hline Epizyotomi & 115 & 100,0 \\
\hline
\end{tabular}

Tablo 3. Gebelerin ve fetüsün bazı sosyo-demografik özellik, Apgar skoru ve doğum eylemi 2. evresi süre ortalamalarının dağılımı ( $\mathrm{n}$ : 485)

\begin{tabular}{|l|c|}
\hline \multirow{2}{*}{ Yaş } & $\mathbf{X} \pm \mathbf{S S}$ \\
\cline { 2 - 2 } Nabız (atım/dk) & $25,8 \pm 5,5$ \\
Bazal kalp atım hızı (mmHg) & $82,9 \pm 4,9$ \\
Doğum eyleminde 2. evrenin süresi (dk.) & $140,4 \pm 11,4$ \\
1. dakika Apgar skoru & $7,7 \pm 0,7$ \\
5. dakika Apgar skoru & $9,2 \pm 0,7$
\end{tabular}

ortalaması 19,7 $\pm 8,3 \mathrm{dk}$. iken bebeklerin 1 . dakika Apgar skoru ortalaması 7,7 $\pm 0,75$. dakika Apgar skoru ortalaması 9,2 $\pm 0,7$ 'dir (Tablo 3).

Normal vajinal doğumdan önce son çekilen EFM sonucuna göre Apgar skoru ortalamalarına bakıldığında; reaktif ve nonreaktif EFM sonucu ile 1. ve 5. dakika Apgar skoru ortalamaları arasındaki farklılık istatistiksel olarak anlamlı bulunmuştur $(p<0.05)$. Reaktif EFM sonucuna göre 1. dakika Apgar skoru ortalaması 7,8 $\pm 0,6$ iken; 5. dakika Apgar skoru ortalaması $9,3 \pm 0,7^{\prime}$ dir. Nonreaktif EFM sonucuna göre 1.

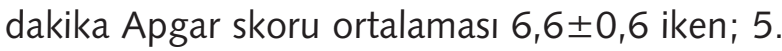
dakika Apgar skoru ortalaması 8,3 $\pm 0,6$ ' dır (Tablo 4).

Doğumda; indüksiyon ve ilaç kullanımı ile reaktif ve nonreaktif EFM sonucu arasındaki ilişki istatistiksel olarak anlamlı bulunurken $(p=0,001)$, yaş ve gebelik sayısı ile reaktif ve nonreaktif EFM sonucu arasındaki ilişki istatistiksel olarak anlamlı bulunmamıştır $(p>0,05)$. Doğum eylemi sırasında indüksiyon $(\% 18,2)$ ve ilaç $(\% 16,5)$ kullanımının nonreaktif EFM sonucunu artırdığı ( $X^{2}: 23,10$; 32,72 ), yaş ve gebelik sayısının ise EFM sonucunu etkilemediği belirlenmiştir $\left(X^{2}: 1,34 ; 0,98\right)$ (Tablo 5).

Şuandaki doğumda; indüksiyon ve ilaç kullanımı, yaş ve gebelik sayısı ile 1. ve 5. dakika Apgar skorları arasındaki farklılık istatistiksel olarak anlamlı bulunmuştur $(p=0.001)$. Indüksiyon ve ilaç kullanılmayan bebeklerin 1. (7,74 20,68 ; $7,85 \pm 0,62)$ ve 5 . dakika $(9,20 \pm 0,72$; $9,31 \pm 0,57)$ Apgar skorları, 36 yaş ve üzerinde olan kadınların bebeklerinin 1. $(7,86 \pm 0,88)$ ve 5 . dakika $(9,45 \pm 0,59)$ Apgar skorları, 1-2 gebelik yaşayan kadınların bebeklerinin 1. $(7,84 \pm 0,71)$ ve 5. dakika $(9,27 \pm 0,72)$ Apgar skorları daha yüksek bulunmuştur (Tablo 6). 
Tablo 4. Normal vajinal doğumdan önce çekilen son EFM sonucuna göre Apgar skoru ortalamalarının dağılımı

\begin{tabular}{|l|c|c|c|c|}
\hline \multirow{2}{*}{ Sonuç } & $\begin{array}{c}\text { 1. dakika } \\
\text { Apgar skoru }\end{array}$ & $\begin{array}{c}\text { 5. dakika } \\
\text { Apgar skoru }\end{array}$ & t & p \\
\cline { 2 - 4 } Reaktif & $\mathrm{X} \pm \mathrm{SS}$ & $\mathrm{X} \pm \mathrm{SS}$ & & 0,001 \\
Nonreaktif & $7,8 \pm 0,6$ & $9,3 \pm 0,7$ & 50,30 & 19,59 \\
\hline
\end{tabular}

Tablo 5. Doğumda yapılan işlemlere ve gebelerin bazı özelliklerine göre EFM sonucunun dağılımı

\begin{tabular}{|c|c|c|c|c|c|c|c|c|}
\hline \multirow{3}{*}{$\begin{array}{l}\text { Doğumda yapılan işlemler } \\
\text { ve gebelerin bazı özellikleri }\end{array}$} & \multicolumn{3}{|c|}{ Sonuc } & \multicolumn{3}{|c|}{ Toplam } & \multirow[b]{3}{*}{$x^{2}$} & \multirow[b]{3}{*}{$p$} \\
\hline & \multicolumn{2}{|c|}{ Reaktif } & \multicolumn{2}{|c|}{ Nonreaktif } & \multirow[b]{2}{*}{ n } & \multirow[b]{2}{*}{$\%$} & & \\
\hline & $\mathbf{n}$ & $\%$ & $\mathbf{n}$ & $\%$ & & & & \\
\hline \multicolumn{9}{|l|}{ Doğumda indüksiyon kullanımı } \\
\hline Kullanıldı & 157 & 81,8 & 35 & 18,2 & 192 & 100,0 & 23,10 & 0,001 \\
\hline Kullanılmadı & 279 & 95,2 & 14 & 4,8 & 293 & 100,0 & & \\
\hline Toplam & 436 & 89,9 & 49 & 10,1 & 485 & 100,0 & & \\
\hline \multicolumn{9}{|l|}{ Doğumda ilaç kullanımı } \\
\hline Kullanıldı & 243 & 83,5 & 48 & 16,5 & 291 & 100,0 & 32,72 & 0,001 \\
\hline Kullanılmadı & 193 & 99,5 & 1 & 0,5 & 194 & 100,0 & & \\
\hline Toplam & 436 & 89,9 & 49 & 10,1 & 485 & 100,0 & & \\
\hline \multicolumn{9}{|l|}{ Yaş } \\
\hline 25 yaş ve altı & 230 & 88,8 & 29 & 11,2 & 259 & 100,0 & 1,34 & 0,510 \\
\hline 26-35 yaş arası & 187 & 91,7 & 17 & 8,3 & 204 & 100,0 & & \\
\hline 36 yaş ve üstü & 19 & 86,4 & 3 & 13,6 & 22 & 100,0 & & \\
\hline Toplam & 436 & 89,9 & 49 & 10,1 & 485 & 100,0 & & \\
\hline \multicolumn{9}{|l|}{ Gebelik sayısı } \\
\hline 1-2 gebelik & 326 & 90,1 & 36 & 9,9 & 362 & 100,0 & 0,98 & 0,610 \\
\hline 3-4 gebelik & 107 & 89,9 & 12 & 10,1 & 119 & 100,0 & & \\
\hline 5 ve üstü sayıda gebelik & 3 & 75,0 & 1 & 25,0 & 4 & 100,0 & & \\
\hline Toplam & 436 & 89,9 & 49 & 10,1 & 485 & 100,0 & & \\
\hline
\end{tabular}

Tablo 6. Doğumda yapılan işlemlere ve gebelerin bazı özelliklerine göre 1. ve 5. dakika Apgar skoru ortalamalarının dağılımı

\begin{tabular}{|c|c|c|c|c|}
\hline \multirow[b]{2}{*}{ Doğumda İndüksiyon } & $\begin{array}{l}\text { 1. dakika } \\
\text { Apgar skoru } \mathrm{X} \pm \mathrm{SS}\end{array}$ & $\begin{array}{c}\text { 5. dakika } \\
\text { Apgar skoru } X \pm S S \text { t } p\end{array}$ & $t$ & $p$ \\
\hline & $7,6 \pm 0,8$ & $9,1 \pm 0,7$ & 35,35 & \multirow{2}{*}{0,002} \\
\hline Kullanılmadı & $7,7 \pm 0,7$ & $9,2 \pm 0,7$ & 40,31 & \\
\hline Doğumda îlaç & & & & \multirow{3}{*}{0,012} \\
\hline Kullanıldı & $7,6 \pm 0,8$ & $9,1 \pm 0,8$ & 40,44 & \\
\hline Kullanılmadı & $7,8 \pm 0,6$ & $9,3 \pm 0,6$ & 35,23 & \\
\hline Yaş & & & & \\
\hline 25 yaş ve altı & $7,7 \pm 0,7$ & $9,2 \pm 0,8$ & 39,38 & \multirow[t]{4}{*}{0,001} \\
\hline 26-35 yaş arası & $7,7 \pm 0,7$ & $9,1 \pm 0,7$ & 34,64 & \\
\hline 36 yaş ve üzeri & $7,9 \pm 0,9$ & $9,4 \pm 0,6$ & 11,20 & \\
\hline Gebelik sayısı & & & & \\
\hline 1-2 gebelik & $7,8 \pm 0,7$ & $9,3 \pm 0,7$ & 49,41 & 0,001 \\
\hline 3-4 gebelik & $7,2 \pm 0,5$ & $8,9 \pm 0,7$ & 24,35 & \\
\hline 5 ve üstü & $6,7 \pm 0,5$ & $8,0 \pm 0,0$ & 5,00 & \\
\hline
\end{tabular}




\section{Tartışma}

Elektronik fetal monitorizasyonun doğum sırasındaki etkinliği, neonatal konvülsiyonları, serebral palsi ya da intrapartum fetal ölüm gibi komplikasyonları azaltması ile ölçülür $(7,9,10,16)$. Elektronik fetal monitör kullanım kolaylığından dolayı obstetrik pratiğin en sık kullanılan aracı olmaya devam etmektedir $(9,16)$. Yapılan çalışmalar elektronik fetal monitörün intrapartum asfiksiyi tespit etmede etkin olduğunu ortaya koymaktadır $(7,9,10,15,17)$. Çalışmamızda gebelerin $\% 89,9$ 'unun normal vajinal doğumdan önce son çekilen EFM sonucunun reaktif olduğu saptanmıştır. Çalışmamız sonucu da yapılan çalışmalardaki gibi elektronik fetal monitörün intrapartum asfiksiyi tespit etmede etkin olduğunu göstermektedir. Bu çalışmaların aksine Matthew Withiam-Leitch ve arkadaşları (2006) ile Ergun ve arkadaşlarının (2012) çalışmalarının sonucunda EFM çeşitli nedenlerle tek başına fetal iyilik halini göstermede tahmin edildiği kadar başarılı bulunmamıştır.

Apgar skoru fetal asfiksiyi belirlemede kullanılan başlıca parametrelerdendir (7). Neonatal değerlendirmede kullanılan Apgar skoru 1. ve 5. dakika skorlarıdır (13). Intrapartum hipoksi sonucunda yenidoğanda Apgar skorunun düşük olması beklenen bir durumdur (20). Altuntaş ve arkadaşları (2013) yaptıkları çalışmada doğan bebeklerin 1. dakika Apgar skoru ortalamasının 8,0 ve 5. dakika Apgar skoru ortalamasının ise 9,1 olduğunu belirtmiştir. Çalışmamızda doğumdan hemen sonra bebeklerin 1. dakika Apgar skoru

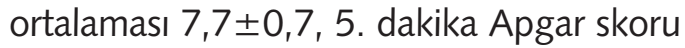
ortalaması 9,2 $\pm 0,7$ 'dir. Altuntaş'ın çalışmasına benzer biçimde çalışmamızda da Apgar skorunun fetal asfiksiyi tespit etmede etkin olduğu görülmektedir. Ancak bu çalışmaların aksine yapılan bazı çalışmalar Apgar skorunun asidozu tespit etmede çok yeterli olmadığını ortaya koymaktadır $(13,22)$.

Düşük Apgar skoru neonatal ensefalopati ve erken neonatal ölümleri önlemede etkilidir (14). Chen ve arkadaşları (2011) ile Ananth ve arkadaşları (2013) yaptıkları çalışmada elektronik fetal monitorizasyon ve düşük Apgar skorunun erken neonatal ölümleri azaltmada etkin olduğunu belirtmişlerdir. Comart ve arkadaşlarının (2007) fetal kalp hızı monitorizasyonu sonuçları ile ilişkili erken neonatal sonuçları değerlendirdiği çalışmada olgu grupları arasında 1. dakika Apgar skoru bakımından anlamlı fark tespit edilmiş $(p=0.006)$, 5. dakika Apgar skoru ortalamaları arasında anlamlı fark tespit edilmemiştir $(p=0.052)$. Çalışmamızda reaktif EFM sonucuna göre 1. dakika Apgar skoru ortalaması 7,8 $\pm 0,6$ iken, 5. dakika Apgar skoru ortalaması 9,3 20,7 'dir. Nonreaktif EFM sonucuna göre 1. dakika Apgar skoru ortalaması 6,6 0,6 iken; 5. dakika Apgar skoru ortalaması 8,3 $\pm 0,6$ 'dır. Vajinal doğumdan önce son çekilen EFM sonucu reaktif olduğunda yenidoğanın Apgar skoru değeri yüksek iken nonreaktif olduğunda Apgar skor değerinin düşük olduğu belirlenmiştir. Çalışma sonucunda Elektronik Fetal Monitorizasyon ve Apgar skorlama sistemi asfiksiyi saptamada etkin bulunmuştur. Yapılan diğer çalışmalardaki gibi bu çalışma doğrultusunda da EFM ve düşük Apgar skor sonuçları arasındaki ilişkinin erken neonatal ölümleri önlemede etkin olduğu söylenebilir.

Doğumun oksitosinle indüksiyonu, spontan doğumlara göre daha fazla variable (değişkenlik) ve geç deselerasyon (fetal kalp atım hızında yavaşlama) gösterme riski taşır (23). Oksitosin indüksiyonunun hiperstimülasyon, sezaryen, hipotansiyon, antidiüretik etki, neonatal hiperbilirübinemi, uterus rüptürü, fetal distres vb. gibi komplikasyonları söz konusudur $(24,25)$. Çalışmamızda doğum eylemi sırasında indüksiyon $(\% 18,2)$ ve ilaç $(\% 16,5)$ kullanımının nonreaktif EFM sonucunu artırdığı bulunmuş olup; indüksiyon ve ilaç kullanılmayan bebeklerin 1. ve 5. dakika Apgar skorları daha yüksek bulunmuştur. Ayrıca az gebelik yaşayan 36 yaş ve üzerinde olan kadınların bebeklerinin 1. ve 5. dakika Apgar skorları yüksektir. Çalışma bulgularımız sentetik oksitosin, valethamat bromid-parasetamol kullanımının ve artan gebelik sayısının asfiksi oranını artıracağını ortaya koymakta olup bu durum düşük Apgar skoru ve nonreaktif EFM sonucu olarak kendisini göstermektedir.

\section{Sonuç ve Öneriler}

Çalışmamız sonucunda elektronik fetal monitorizasyon ve Apgar skor sonuçları asfiksiyi saptamada ve erken neonatal ölümleri önlemede etkin bulunmuştur. İntrauterin fetal sağlığın değerlendirilmesinde EFM, yenidoğanda Apgar skorlama sisteminin kullanılması perinatal ölümlerin önlenmesine ve sağlıklı toplum oluşmasına katkı sağlamaktadır. Bu sonuçlar doğrultusunda EFM, Apgar skorlama sisteminin doğum salonlarında etkin bir biçimde kullanılması önerilmektedir. 
İletişim: Dr. Gülbahtiyar Demirel

E-posta: gulbahtiyar_doganer@hotmail.com

\section{Kaynaklar}

1.Beksaç MS. Maternal-fetal tıp ve perinatoloji. Ankara: Medical Network; 2001.

2.Okosun $\mathrm{H}$, Arulkumaran S. Intrapartum fetal surveillance. Curr Obstet Gynecol 2005;15:18-24.

3. Tokat MA, Okumuş H, Demir N. Elektronik fetal izlem eğitiminin ebe ve hemşirelerin bilgi ve yorumlama becerilerine etkisi. DEUHYO ED 2011;4(2):63-6.

4.Van Geijn HP. Intrapartum fetal heart rate monitoring. International Congress Series 2005;1279:332-7.

5.ACOG. Intrapartum fetal heart rate monitoring: Nomenclature, interpretation and general management principles. ACOG Practice Bulletin No 106. Obstet Gynecol 2009;114(1):192-202.

6.Aktaş S, Osmanağaoğlu MA. İntrapartum elektronik fetal monitorizasyon uygulaması ve sağlık profesyonellerinin sorumlulukları. Life Sciences 2017;12(1):14-29.

7. Comart N, Yıldırım G, Güngördük K, Aktaş FN, Ark C. Elektronik fetal kalp hızı mönitörizasyonu: normal monitör, fetal stres, fetal distres ile ilişkili erken neonatal sonuçlar. Türkiye Klinikleri J Gynecol Obst 2007;17(3):186-95.

8. Freeman R, Garite T, Nageotte M. Fetal kalp hızı monitorizasyonu. Çev Edit. Recep Has. 1. Baskı. İstanbul: Nobel Matbaacılık; 2006. s. 8-21.

9. Ananth CV, Chauhan SP, Chen HY, D'Alton ME, Vintzileos AM. Electronic fetal monitoring in the United States: temporal trends and adverse perinatal outcomes. Obstet Gynecol 2013;121(5):927-33.

10. Chen HY, Chauhan SP, Ananth CV, Vintzileos AM, Abuhamad AZ. Electronic fetal heart rate monitoring and its relationship to neonatal and infant mortality in the United States. Am J Obstet Gynecol 2011;204(6):491.e1-e10.

11. Hanson L. Risk management in intrapartum fetal monitoring: accidental recording of the maternal heart rate. J Perinat Neonat Nurs 2010;24(1):7-9.

12. Çetin A. Use of three-tier classification system during intrapartum electronic fetal heart rate monitoring. Basic and Clinical Sciences 2010;1(4):71-6.

13. Köse $O$, Özdemir S. Fetal mordiditeyi öngörmede umblikal arter kan $\mathrm{pH}^{\prime} \mathrm{s}$ ve birinci dakika Apgar skorunun değerleri. KÜ Tıp Fak Derg 2013;15(3):914.
14. American College of Obstetricians and Gynecologists. The Apgar score. Committee Opinion No 644. Obstet and Gynecol 2015;126(4): e52-5.

15. Dellinger $\mathrm{EH}$, Boehm FH, Crane MM. Electronic fetal heart rate monitoring: early neonatal outcomes associated with normal rate, fetal stress and fetal distress. Am J Obstet Gynecol 2000;182(1):214-20.

16. Schwartz N, Young BK. Intrapartum fetal monitoring today. J Perinat Med 2006;34(2):99107.

17. Parer JT, King T, Flanders $S$, Fox $M$, Kilpatrick SJ. Fetal acidemia and electronic fetal heart rate patterns: is there evidence of an association?. The Journal of Maternal- Fetal and Neonatal Medicine 2006;19(5):289-94.

18. Withiam-Leitch $M$, Shelton J, Fleming E. Central fetal monitoring: effect on perinatal outcomes and cesarean section rate. Birth 2006;33(4):284-8.

19. Ergun $B$, Şen $S$, Kılıç Y, Kuru O, Özsürmeli M. Fetal distres endikasyonuyla sezaryen doğum yapmış olgularda non-stres testin karar vermedeki rolü: Kliniğimizin verileri ile literatür derlemesi. Türk Jinekoloji ve Obstetrik Derneği Dergisi 2012;9(1):59-64.

20. Tokat MA, Okumuş $H$, Demir N. Gebelikte ve doğum eyleminde elektronik fetal izlem. Birinci Baskı. İstanbul: Deomed Yayıncılık; 2013.

21. Altuntaş $H$, Dansuk R, Köse $O$. Sezaryen oranlarının çeşitli değişkenlere bağlı olarak değerlendirilmesi. KÜ Tıp Fakültesi Dergisi 2013;15(2):1-7.

22. Şentürk A, Arıgüloğlu EA, Tekirdağ Ai. Travaydaki fetusta fetal iyilik halinin belirlenmesinde elektronik fetal monitorizasyonun yeri. Perinatoloji Dergisi 1997;5(1-2):28-31.

23. Jozwiak M, Bloemenkamp KW, Kelly AJ, Mol BW, Irion $\mathrm{O}$, Boulvain M. Mechanical methods for induction of labor. Cochrane database Syst Rev 2012;14(3): CD001233.

24. Clark SL, Miller DD, Belfort MA, Dildy GA, Frye DK, Meyers JA. Neonatal and maternal outcomes associated with elective term delivery. American Journal of Obstetrics and Gynecology 2009;200(2):156.e1-e4.

25. Cunningham FG, Leveno KJ, Bloom SL, Hauth JC, Rouse DJ, Spong CY. Williams obstetrik. Çev. Ceylan Y, Yıldırım G, Gedikbaşı A, Aslan H, Gül A. 23. ed. İstanbul: Nobel Tıp Kitabevi; 2010. s.500-10. 